\title{
Individual Values and SME Environmental Engagement
}

\section{Anja Schaefer', Sarah Williams², and Richard Blundel'}

\begin{abstract}
We study the values on which managers of small and medium-sized enterprises (SMEs) draw when constructing their personal and organizational-level engagement with environmental issues, particularly climate change. Values play an important mediating role in business environmental engagement, but relatively little research has been conducted on individual values in smaller organizations. Using the Schwartz Value System (SVS) as a framework for a qualitative analysis, we identify four "ideal-types" of SME managers and provide rich descriptions of the ways in which values shape their constructions of environmental engagement. In contrast to previous research, which is framed around a binary divide between self-enhancing and self-transcending values, our typology distinguishes between individuals drawing primarily on Power or on Achievement values and indicates how a combination of Achievement and Benevolence values is particularly significant in shaping environmental engagement. This demonstrates the theoretical usefulness of focusing on a complete range of values. Implications for policy and practice are discussed.
\end{abstract}

\section{Keywords}

environmental engagement, individual values, Schwartz Values System, small and medium-sized enterprises

\footnotetext{
'The Open University, Milton Keynes, UK

2University of Bedfordshire, Bedford, UK

Corresponding Author:

Anja Schaefer, Department of Public Leadership and Social Enterprise, The Open University Business School, Michael Young Building, Walton Hall, Milton Keynes MK7 6AA, UK.

Email: anja.schaefer@open.ac.uk
} 
This article addresses the research question how owners and senior managers of small and medium-sized enterprises (SMEs) draw on individual values as they seek to make sense of environmental issues in their organizations.

The objectives of the article are (a) to identify the configuration of values upon which managers draw in constructing their businesses' environmental engagement; (b) to develop a typology of four "ideal-types" of SME managers with respect to environmental engagement, based on these value configurations; and (c) to provide rich descriptions of the way in which these values are drawn upon in managers' constructions of environmental engagement.

SMEs' response to environmental challenges is important on a practical and policy level. While individual environmental impacts are less than those of larger businesses, they have a considerable combined impact (European Commission, 2016; Kearins, Collins, \& Tregidga, 2010) and offer considerable potential as sources of eco-innovation and proenvironmental influence (Jamali, Lund-Thomsen, \& Jeppesen, 2017).

Governments and business support organizations continue to promote SME environmental engagement mainly on the basis of a "win-win" rationale, where proenvironmental investments will simultaneously reduce costs or increase competitiveness (European Commission, 2011; Revell, Stokes, \& Chen, 2010). However, securing SME engagement is difficult (Gadenne, Kennedy, \& McKeiver, 2009; Revell \& Blackburn, 2007) as SMEs often struggle to comply with environmental regulation (Baden, Harwood, \& Woodward, 2009; Cassells \& Lewis, 2011) or remain unconvinced by conventional "win-win" arguments (Vickers, Vaze, Corr, Kasparova, \& Lyon, 2009).

There is evidence that where SMEs engage positively with environmental issues, it is often prompted by the personal values of their owners and senior managers (Berrone, Cruz, Gomez-Mejia, \& Larraza-Kintana, 2010; Brammer, Hoejmose, \& Marchant, 2012). However, the role of values in SME environmental engagement remains underresearched. Most studies focus on large firms and either make a broad, binary distinction between self-transcending and self-enhancing values (Florea, Cheung, \& Herndon, 2013; Fritzsche \& $\mathrm{Oz}, 2007 ; \mathrm{Ng} \&$ Burke, 2010) or focus on a very narrow range of values (Chin, Hambrick, \& Treviño, 2013; Mudrack, 2007). Studying individual values in an SME context is important because (a) smaller enterprises are often created out of personal convictions rather than for purely financial reasons, and (b) owner-managers in particular tend to have more wide-ranging strategic control than managers of large firms, so their values can have a more direct influence on its overall direction (Spence, 2016).

Recent research suggests that the communication of global environmental problems to lay audiences' would benefit from starting with people's own 
values (Corner \& Clarke, 2017; Whitmarsh \& Corner, 2017). While this also seems a promising approach for environmental policy and practice among SMEs, further research is needed to gain a deeper theoretical and practical understanding of the underlying processes.

In this article, we use the 10 value domains developed by Schwartz and coauthors (Schwartz, 2012; Schwartz \& Bilsky, 1987, 1990) as a theoretical framework to analyze in-depth, qualitative data gained from interviews with SME owners and senior managers. Our aim is to develop a fine-grained picture of the role of individual values in SME environmental engagement, yielding additional empirical evidence to guide policy in this area (cf. Spence, 2016). By applying the Schwartz framework in a detailed and systematic analysis of this insufficiently understood phenomenon (cf. Crane, Henriques, Husted, \& Matten, 2016), we provide a new, robust theoretical basis for classifying SME managers in terms of their environmental engagement. Future research can build on our ideal-types to generate further, nuanced insights into such questions as the influence of different types of ownership on SME environmental engagement or to compare them with larger companies. Through rich, qualitative descriptions of how different value configurations shape SME managers' understanding of and engagement with environmental issues, we aim to capture the "emotionally charged, value-laden" nature of these processes and contribute to a widening of the "methodological horizons" of the field (Poldner, Shrivastava, \& Branzei, 2017, p. 215).

\section{Literature Review and Theoretical Framework}

Rokeach (1968) defined values as enduring beliefs that a specific mode of conduct is personally or socially preferable to an opposite mode of conduct. Values are activated within situations (Schwartz, 2004), leading individuals to privilege certain actions over others, and influencing their attention, perception, and interpretation of that situation. This process has particular relevance in organizational settings, as "the way in which environmental threats such as climate change are perceived by business owners and managers can have a significant impact on firm-level behaviour and on its interactions with other actors in their institutional field" (Rothenberg \& Levy, 2012, p. 54).

Values in business can be researched at the individual, organizational, institutional, or national level (Agle \& Caldwell, 1999). This article is concerned with how individual values shape the way in which decision makers make sense of social and environmental responsibilities in business (Hahn, Pinkse, Preuss, \& Figge, 2015). It builds on previous studies, which have 
taken a more general perspective on links between values and business engagement (Desai \& Rittenburg, 1997; Goodpaster \& Matthews, 1982) or focused on a very small range of specific values and contexts (Chin et al., 2013; Duarte, 2010; Mudrack, 2007).

A few large company studies have examined how self-enhancing versus self-transcending values relate to managers' approaches to corporate social responsibility (CSR), sustainability, and ethics, finding altruistic values positively related to particular ethical and sustainable management practices (Florea et al., 2013; Fritzsche \& Oz, 2007; Ng \& Burke, 2010). In an SME context, Spence and Rutherfoord (2001) developed a $2 \times 2$ typology of managers' perspectives on the business-society relationship, locating profit maximization versus profit satisficing and socially active versus inactive on each axis. While not explicitly based on values, this framing has parallels with orientations toward self-enhancement (particularly wealth) versus self-transcendence.

For the association of individual values with proenvironmental and prosocial initiatives to apply, managers need to have discretion over decision making. Otherwise tensions may arise between sustainability initiatives highly valued by individual managers and business agendas (Hahn et al., 2015), and managers may feel they have to accommodate their values to those of the organization (Hemingway \& Maclagan, 2004). Such disparities may be less frequent in smaller businesses because firm-level behavior, including environmental and social engagement, is often influenced by owner-managers' individual values (Boiral, Baron, \& Gunnslaugson, 2014; Cambra-Fierro, Hart, \& Polo-Redondo, 2008; Jansson, Nilsson, Modig, \& Hed Vall, 2017).

The distinction between self-enhancing and self-transcending values adopted in earlier research is based on systematic psychological classifications of values but it looks at only one dimension of the Schwartz Value System (SVS), a more fine-grained classification of 10 different value domains (Schwartz, 2012; Schwartz \& Bilsky, 1987, 1990). There is a lack of systematic, in-depth evidence on how these value domains relate to managers' engagement with environmental issues. We adopted the SVS as our analytical framework for three reasons: (a) it provides a good compromise between detail and parsimony by classifying a wide range of individual values along two dimensions, (b) it has been applied successfully in previous work on environmental engagement and business social responsibility (Mirosa, Lawson, \& Gnoth, 2013; Onkila, 2009), and (c) marker value descriptions for the 10 value domains facilitated a more rigorous qualitative analysis (Ralston et al., 2011; Schwartz \& Bilsky, 1990). 


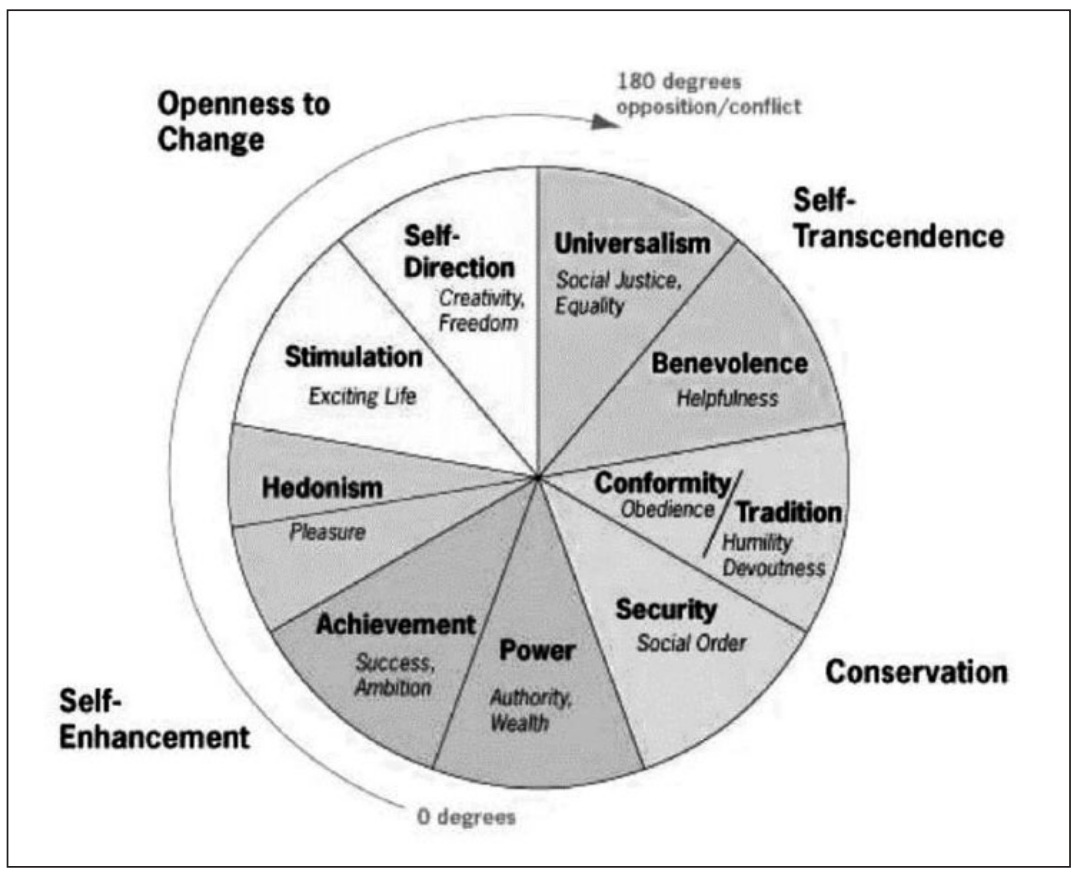

Figure I. The Schwartz Circumplex Model. Source. Adapted from Schwartz (20I2).

Schwartz and coauthors posit that values form a dynamic, interdependent system, where some values are closely related and thus compatible, whereas others stand in opposition to each other (Schwartz, 1994, 2012; Schwartz \& Bilsky, 1987, 1990). The SVS defines 10 value domains, each of which is represented by several marker values. The value domains fall into two dimensions: Self-Enhancement versus Self-Transcendence and Conservation versus Openness-to-Change, represented in a Circumplex Model (Figure 1).

The SVS postulates that adjacent values are compatible with each other, whereas values on opposite sides of the continuum are in conflict. Thus, selftranscending and self-enhancing values are less likely to be activated simultaneously than values that are closer to each other. Schwartz and Bilsky (1990) highlighted a particular tension between concern for the welfare of others and task achievement, whereas domains such as Conformity and Security, or Achievement and Hedonism, are more compatible. 
Self-transcending values have been found to be positively related to environmental and social engagement in business, whereas self-enhancing values are negatively related (Florea et al., 2013; Fritzsche \& Oz, 2007; $\mathrm{Ng} \&$ Burke, 2010). However, the postulated tension between them raises important questions over widely adopted "win-win" arguments for business responsibility (cf. Elkington, 1994; Porter \& Kramer, 2011). As Crompton (2010) argued, the case for a simultaneous pursuit of financial and environmental goals rests on two seemingly conflicting value domains: Power (self-enhancing), particularly pursuit of wealth and competitiveness, and Universalism (self-transcending), expressed through environmental protection and unity with nature. Hahn and colleagues (2015) and van der Byl and Slawinski (2015) argued that CSR should therefore be about overcoming tensions between individual values and organizational objectives rather than achieving "win-win" outcomes. A more detailed examination of managers' individual values will be valuable in ascertaining whether the "win-win" arguments are indeed built on contradictory foundations.

Schwartz and Bilsky (1990) further suggested that the prevalence and compatibility of particular value domains may vary depending on the concrete action context in which they are activated. Studies into different action contexts, such as work (Wöhrmann, Fasbender, \& Deller, 2016), political attitudes and activism (Rathburn, Kertzer, Reifler, Goren, \& Scotto, 2016), and social issues (Arikan, Ben-Nun, \& Bloom, 2015) found different combinations of value domains to relate to contrasting attitudes and behaviors. Onkila (2009) found that corporate environmental statements tended to draw on Power values; and Mirosa, Lawson, and Gnoth (2013) found that Achievement values were most influential in motivating people to save energy in their homes. There is, however, no extant work that addresses environmental engagement of SME managers as an action context, or that examines all 10 SVS domains, as opposed to a binary distinction between self-enhancing and self-transcending values. Addressing this gap will add to our understanding of the role of values in this particular setting and contribute to the study of values in different action contexts.

A final salient point is that the SVS refers to a structure of values. Individuals activate sets of values in particular situations and their behavior at any given point in time is usually motivated by a conjunction of values rather than single values in isolation (Schwartz \& Bilsky, 1987). This reinforces the importance of considering configurations of value domains, rather than individual value domains, when researching environmental engagement. 
In summary, existing research into managers' individual values and business environmental engagement could be usefully extended by (a) looking in detail at the way in which values are drawn upon in the particular context of SME environmental engagement as this is likely to be different from values being elicited in the abstract; (b) looking at the entire range of value domains identified in the Schwartz model - rather than just the overarching dimensions; and (c) looking at value domain configurations to understand which value domains may work in tandem to encourage environmental engagement and which may be incompatible in a specific context.

\section{Method}

This article forms part of a broader study, aimed at understanding how SME managers made sense of climate change and other environmental concerns, including the reasons why participants did or did not engage with these issues. Individual values were one of the most prominent themes identified during analysis of the initial interviews because it infused the way that participants constructed their accounts. As a consequence, our main data analysis phase was designed to account for this emerging story about values.

The research focused on SMEs located in the counties of Bedfordshire, Cambridgeshire, Suffolk, and Essex in the South-East of England. The region contains a mixture of urban and rural populations, and covers a wide range of industry sectors. A number of local environmental characteristics were expected to increase the salience of climate change concerns for participants: It is a low-lying area of England, identified by the U.K. Climate Impacts Project (Willows \& Connell, 2003) as vulnerable to extreme weather effects such as drought, heat waves, flooding, and sea level rises. However, both the region and the specific participating businesses were chosen to be prototypical rather than extreme cases (Eisenhardt, 1989).

\section{Sample Selection}

SMEs for this study were defined as independent limited companies (not a sole trader or partnership) with fewer than 250 employees (Department for Business, Innovation and Skills, 2015), with actual company size in our sample ranging from five to 80 employees. Following a purposive sampling strategy, we aimed to include a variety of participants, both in terms of the nature of the business (different sizes, sectors, and level of environmental engagement as far as possible to tell in advance) and in terms of the demographic characteristics of the participants themselves (see Table 1 for an overview). 
Table I. Overview of Participants.

\begin{tabular}{|c|c|c|c|c|c|}
\hline ID code & Gender & Age & $\begin{array}{l}\text { Position in } \\
\text { company }\end{array}$ & Company sector & $\begin{array}{l}\text { Company } \\
\text { size }\end{array}$ \\
\hline MI & Male & $55-60$ & Director & Manufacturing & 80 \\
\hline M5 & Female & $40-45$ & $\mathrm{MD} / \mathrm{O}$ & Hospitality (2 participants & 5 \\
\hline M6 & Male & $45-50$ & $\mathrm{MD} / \mathrm{O}$ & in same firm) & 5 \\
\hline M7 & Male & $35-40$ & $\mathrm{MD} / \mathrm{O}$ & Transport & II \\
\hline M8 & Male & $35-40$ & $\mathrm{MD} / \mathrm{O}$ & Food logistics & 15 \\
\hline M9 & Male & $45-50$ & $\mathrm{MD} / \mathrm{O}$ & Transport & 5 \\
\hline MIO & Male & $45-50$ & MD & Architects (2 participants & 60 \\
\hline MII & Male & $35-40$ & FD & in same firm) & 60 \\
\hline MI2 & Male & $45-50$ & $\mathrm{MD} / \mathrm{O}$ & Logistics & 25 \\
\hline MI3 & Male & $60-65$ & Volunteer & Community center & 16 \\
\hline MI4 & Male & $50-55$ & $\mathrm{MD} / \mathrm{O}$ & IT services & 25 \\
\hline MI5 & Female & $50-55$ & $\mathrm{MD} / \mathrm{O}$ & IT services & 7 \\
\hline MI6 & Male & $45-50$ & $\mathrm{MD} / \mathrm{O}$ & Fire safety service & 5 \\
\hline MI7 & Male & $55-60$ & $\mathrm{MD} / \mathrm{O}$ & Marketing & 12 \\
\hline MI8 & Male & $30-35$ & $\begin{array}{c}\text { Franchise } \\
\text { partner }\end{array}$ & Catering & 65 \\
\hline MI9 & Female & $50-55$ & $\mathrm{MD} / \mathrm{O}$ & $\begin{array}{l}\text { Health, Safety and } \\
\text { Environment consultancy }\end{array}$ & 30 \\
\hline $\mathrm{M} 20$ & Male & $50-55$ & $\begin{array}{l}\text { Managing } \\
\text { partner }\end{array}$ & Legal services & 60 \\
\hline M2I & Male & $45-50$ & $\begin{array}{l}\text { Operations } \\
\text { director }\end{array}$ & Equipment distributor & 50 \\
\hline M22 & Male & $45-50$ & $\mathrm{MD} / \mathrm{O}$ & Management consultancy & 15 \\
\hline M23 & Male & $50-55$ & $\mathrm{MD} / \mathrm{O}$ & Distribution & 10 \\
\hline M24 & Female & $50-55$ & MD & Manufacturing & 27 \\
\hline M25 & Male & $45-50$ & $\mathrm{MD} / \mathrm{O}$ & Equipment refurbishment & 12 \\
\hline M26 & Male & $45-50$ & $\mathrm{MD} / \mathrm{O}$ & Marketing consultancy & 8 \\
\hline
\end{tabular}

Note. The missing M2, M3, and M4 in this table were codes assigned to three participants in the earlier pilot study who could not be reinterviewed for this study. FD = Financial Director; $\mathrm{MD} / \mathrm{O}=$ Managing Director/Owner; MD = Managing Director; IT = Information Technology.

Initial participants were identified through the field researcher's preexisting contacts in local business support organizations, previous workshops, and a pilot study with nine SMEs in the same region, conducted 18 months earlier. Findings from the pilot also provided an opportunity to refine our interview schedule and overall approach. Further participants were identified according to the same sampling criteria, using social network sites, general networking events, business presentations, and personal recommendations from early 
participants. Six of the participants had also been interviewed for the pilot (Table 1). Reinterviewing these individuals, who were all embedded in local business networks, provided an opportunity to get deeper insights into changing issues and regional developments.

We conducted a total of 23 semistructured interviews with owner-managers or senior managers in 21 firms. In two firms, we interviewed two joint owner-managers. The senior managers who were not owner-managers included several who performed roles equivalent to a managing director, though titles differed depending on the legal nature and ownership structure of the firm, as well as a financial director and an operations director. All participants had either wide-ranging strategic control or significant influence on the strategic direction of the firm.

We went to considerable efforts to recruit SME managers who were skeptical of environmental issues through generic (i.e., not environment focused) business networking events, contacts in local authorities, local chambers of commerce, and the Business Live networking organization. This proved challenging, perhaps due to higher levels of SME environmental engagement in comparison with those reported in earlier studies (Brammer et al., 2012; Cassells \& Lewis, 2011; Williams \& Schaefer, 2013) or because those entirely uninterested in environmental issues are less likely to agree to be interviewed. Our final sample included three participants who described themselves as having little interest in environmental issues.

\section{Steps in Moving Between Theory and Data}

Inductive or abductive qualitative research typically goes through several cycles of moving between theory and data collection and analysis. The rigor of qualitative research partly depends on making these iterative moves between theory and data transparent (Gioia, Corley, \& Hamilton, 2013). The steps of initial theorizing, data collection, data analysis, and further theory development are summarized in Table 2.

Interview questions and the first order codes were not based on the SVS-ensuring that values that surfaced in the interviews were not inadvertently introduced by our own questions and thus increasing robustness of our findings. However, the SVS, including the detailed descriptions of markers for each value domain, provided the second order coding framework (Ralston et al., 2011). By looking for interview passages that used language similar to the marker values as they are expressed in the Schwartz survey instrument, we were able to interpret such passages as 
drawing on particular values. Sometimes values were explicitly expressed and sometimes they were implied, requiring close attention to both explicit and implicit meanings and use of professional judgment by the coder (M. Mirosa, personal communication, November 2012; Onkila, 2009). The following example demonstrates how interview excerpts were coded for particular marker values. It also illustrates how text can be coded for more than one set of values.

\section{Sample text:}

M25: "If I don't run the business, Africa will suffer, what I do out there, so l've got to keep it going, if I don't get the business right my wife is going to suffer, if I don't get the business right, I mean it's no good collapsing a business, because my business sustains 17 people. So it's got to be running right, and if one person's going to let it down, to be honest, I'll get rid of them because I can't watch 17 people go under" (Original transcript, p. 13).

\section{Values: Power; authority, the right to lead and command}

"If I don't run the business, Africa will suffer, what I do out there, so l've got to keep it going, if I don't get the business right my wife is going to suffer, if I don't get the business right, I mean it's no good collapsing a business, because my business sustains $I 7$ people. So it's got to be running right, and if one person's going to let it down, to be honest, I'll get rid of them because I can't watch I 7 people go under."

The keywords (highlighted) illustrate power, in particular the marker authority, the right to lead and command. M25 is in charge of his business; he leads it; he controls and commands it. The business is about what he does and he requires those working for him to work his way in order for it to be right.

\section{Values: Benevolence; responsible, dependable, reliable}

"If I don't run the business, Africa will suffer, what I do out there, so l've got to keep it going, if I don't get the business right my wife is going to suffer, if I don't get the business right, I mean it's no good collapsing a business, because my business sustains 17 people. So it's got to be running right, and if one person's going to let it down, to be honest, I'll get rid of them because $\mathbf{I}$ can't watch I 7 people go under."

The keywords highlighted here illustrate benevolence, particularly the marker responsible, dependable, reliable. The background information collected by the field researcher make it clear that the reference to Africa is to a specific community group that M25 is working with in partnership with a local community Church, where he described how he had bought land, built an orphanage, and is growing food crops. The reference is therefore attributed to Benevolence rather than Universalism on the basis that the concern is specific to a particular group of people of direct concern to the individual, rather than to a more generalized category. 


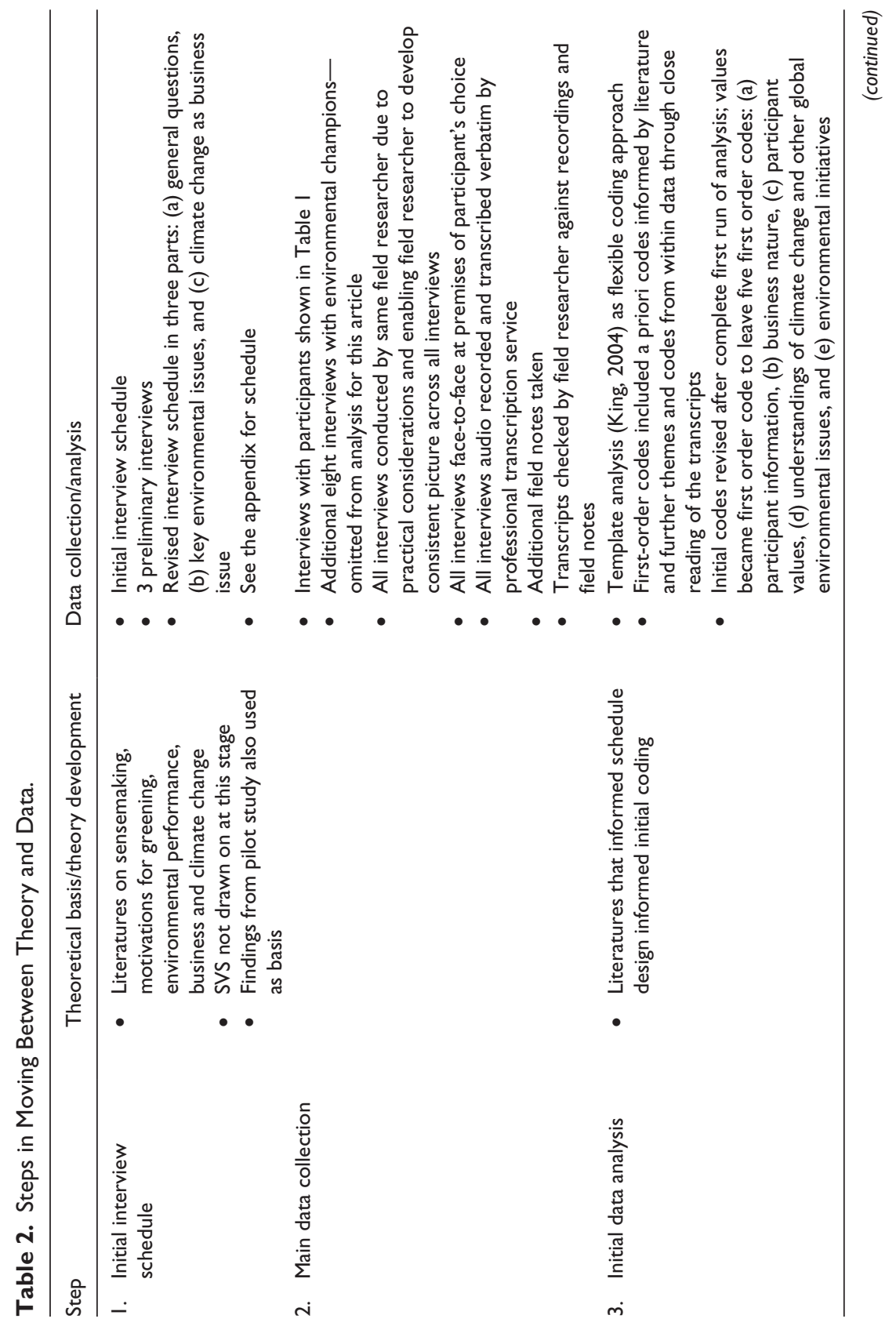




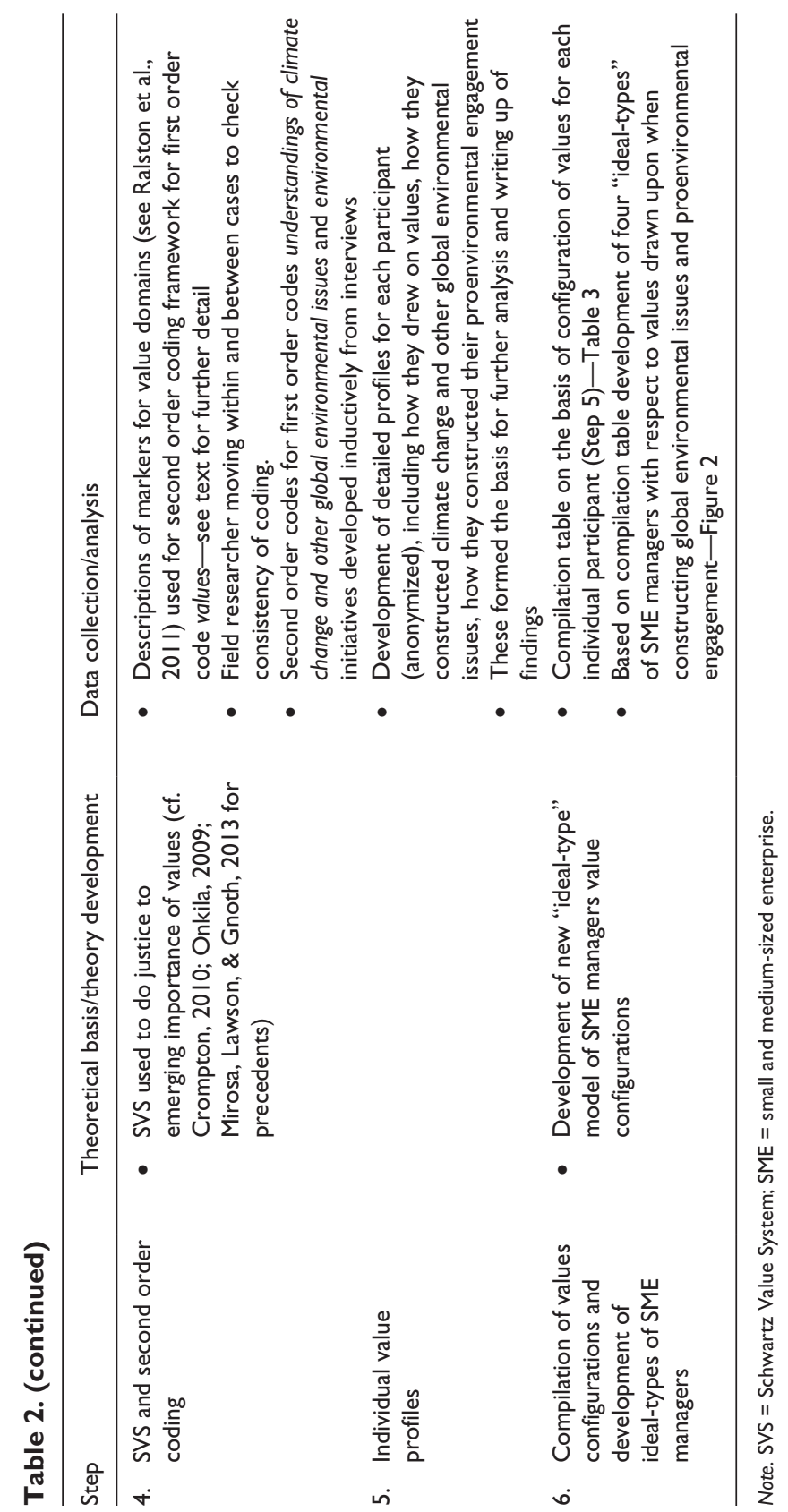




\section{Robustness of Method}

In addition to nondirective questioning, we adopted several steps to increase robustness of our methods. The interviews and coding were carried out by one highly experienced field researcher, whose familiarity with the context allowed her to gain participants' trust, to ask more insightful questions, and to maintain an overview across all interviews. The additional information gained from conducting all the interviews enabled the field researcher to interpret the data more meaningfully than if interviews had been conducted and coded by different researchers (Gioia et al., 2013; Lincoln \& Guba, 1985). The field researcher's prolonged engagement through her long-standing work as an SME environmental advisor, the pilot study, and a number of preliminary conversations with key informants as well through subsequent engagement with local SMEs increased the credibility of the data analysis (Lincoln \& Guba, 1985).

The coauthors of this article provided peer debriefings (Lincoln \& Guba, 1985), offering an outsider perspective to prevent the field researcher becoming too close to the participants' views (Gioia et al., 2013). During Step 4, the coding for values using the SVS, all three authors examined several extended passages from the transcripts to increase the robustness of the coding. As suggested by Gioia and colleagues (2013), we checked data, codes, interpretations, and emerging findings with research participants and other SME managers and business advisors at various points in the research. Emerging findings were also shared and checked for plausibility with these individuals, as well as during ongoing business support events. After completion of the research project, the findings were used in several further workshops with SMEs from the region. On all these occasions, the data presented, their interpretation, and the conclusions drawn from it rang true with the research participants and other knowledgeable stakeholders. We therefore consider our findings to be credible within the framework proposed by Lincoln and Guba (1985).

\section{Findings}

We start this section with a general overview of the main value configurations, or combinations of value domains that participants drew upon in the interviews (Table 3). These do not necessarily represent all of the values that an individual might draw upon in daily life, merely those demonstrated in interviews related to this specific action context. We then present four ideal-types of SME managers based on these value configurations (Figure 2). Finally, we provide thick descriptions of the ways in which values suffused participants' construction of environmental issues and their own business environmental engagement. 


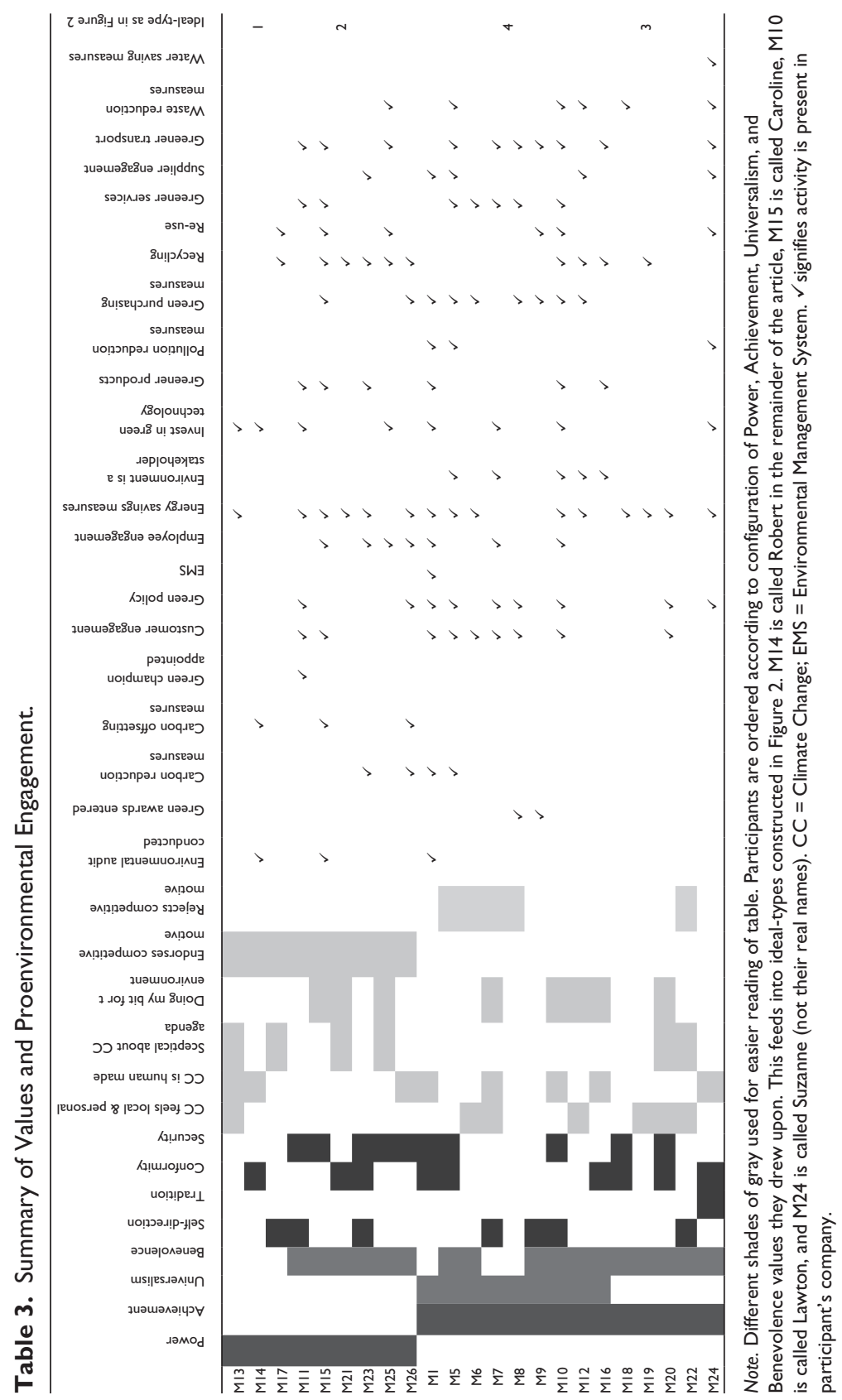




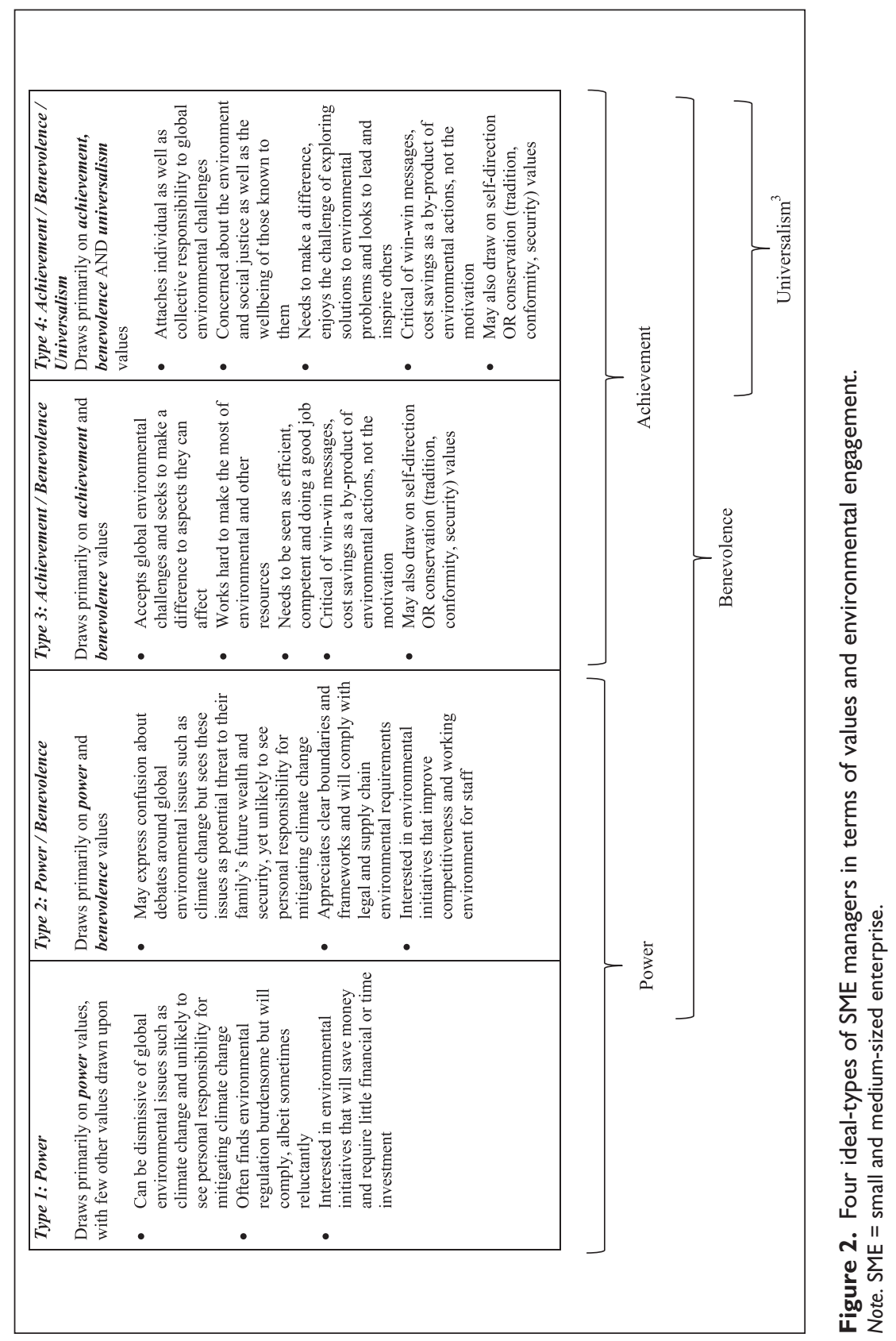


We found instances of participants drawing on eight of the Schwartz value domains, the exceptions being Hedonism and Stimulation. All participants drew on one or more self-enhancing values and, with two exceptions, some self-transcending values. This is consistent with Segal and Lerner's (2013) argument that business managers often hold and activate both types of value. Contrary to conventional expectations of business contexts, Achievement (e.g., realizing ambitions) was the most common self-enhancing value domain, rather than Power (e.g., securing wealth). Participants who predominantly drew on Achievement values would often draw on two self-transcending domains, Universalism as well as Benevolence. By contrast, those drawing mostly on Power values would often also draw on Benevolence but not on Universalism.

Interviewees also drew on values on the Openness to Change/Conservation axis. Self-Direction was drawn upon by many and could be positively or negatively related to environmental engagement (being able to make a difference vs. not liking to be told what to do). Conformity with norms and expectations was also important to several participants and was commonly expressed as a wish to comply with environmental regulation. Several participants drew on Security values, for example, in terms of environmental degradation threatening the future well-being of humankind in general or their children and grandchildren in particular.

As one of the steps in the analysis, we compiled Table 3, showing the values drawn upon by each individual manager. These individual value configurations were then used to develop the four ideal-types presented below.

Table 3 shows a clear separation of participants drawing on Power and participants drawing on Achievement. It also shows that SME managers drawing primarily on Power did not draw on Universalism, although they might draw on Benevolence. By contrast, Achievement values might be combined with Universalism and/or Benevolence. This suggests that some but not all self-enhancing and self-transcending values can be compatible in this action context. These findings challenge Schwartz and Bilsky's (1990) suggestion that care for others and care for one's own achievement are not easily compatible, and studies that identify self-transcending values as the only types conducive to business social and environmental engagement (Fritzsche $\& \mathrm{Oz}, 2007)$. They also demonstrate the merit of an analysis that examines each of the 10 value domains and not merely broad distinctions along the "self-transcendence vs. self-enhancement" and "openness-to-change vs. conservation" axes.

While Table 3 also shows that participants drew on a variety of values on the openness-to-change versus conservation axis, no clear pattern emerged of how these values fitted into any overall value configuration. Perhaps most 
notable is the tendency to draw on Security and Conformity, suggesting that these value domains can play a potentially important role in shaping proenvironmental SME engagement.

In terms of specific responses to climate change, Table 3 indicates the importance of competitiveness motivations for proenvironmental actions, whether participants felt they needed to take personal and/or shared responsibility for mitigating climate change impacts, and a rough indication of the types of actions they had taken in their businesses. This suggests that those SME managers who failed to draw on any self-transcending values had also introduced very few proenvironmental initiatives.

\section{Four Types of SME Managers in Terms of Values and Environmental Engagement}

From our findings, we constructed four ideal-types of SME manager in terms of the value configurations they draw upon in their environmental engagement (Figure 2). We use the ideal-type construct in a broadly Weberian sense, as a tool to assist in making analytical comparisons between concrete cases, and not as a representation of particular individuals.

Several features of this typology need to be highlighted at the outset.

First, it applies to individuals, not firms, and is based on the underlying values that managers seem to draw upon, rather than on their behaviors or attitudes.

Second, it is deliberately not presented as a $2 \times 2$ matrix. While there is a clear and mutually exclusive distinction between the types that draw on Power (Types 1 and 2) and those that draw on Achievement (Types 3 and 4), other distinctions are more gradual. Type 1 draws predominantly on Power, with some participants also drawing on some Security values. Types 2, 3, and 4 all draw on Benevolence in addition to Power (Type 2) or Achievement (Types 3 and 4). The main distinction between Types 3 and 4 is that Type 4 draws on Universalism, whereas Type 3 does not. All types may also draw on other values, such as Security, Conformity, Tradition, and Self-Direction.

Third, our typology is not meant to imply a developmental trajectory from one type to another. Fundamental values, while activated selectively depending on the situation, are thought not to be susceptible to much change over time. As a consequence, it seems unlikely that individuals would move easily between types.

Fourth, all the value configurations were potentially conducive to some form of environmental engagement, with the exception of some Type 1 participants. However, there were differences in how the four types understood environmental challenges and related them to their own business. 
Finally, most of our participants fell into one of the ideal-types but exhibited the associated characteristics to varying degrees. In the remainder of this section, we provide rich descriptions to show how participants of each type drew on the 10 value domains. We focus particularly on the anonymized profiles of four SME managers who illustrate features of each of the four ideal-types particularly well, augmented by relevant evidence from other participants:

- Robert (M14)-Type 1; Managing Director of an Information Technology company that employs 27 staff;

- Caroline (M15)-Type 2; Managing Director of an Information Technology company that employs seven staff;

- Suzanne (M24) - Type 3; Managing Director of a manufacturing company with 27 employees; and

- Lawton (M10)-Type 4; Managing Director of a service firm that employs 60 staff.

\section{Drawing on Power-Type I and Type 2 Managers}

In this section, we illustrate how Type 1 and Type 2 managers drew on different aspects of Power and Benevolence to construct their environmental engagement (or, in a few cases, nonengagement). We also show how they drew on Security and Self-direction values in addition to Power and Benevolence.

Power values. Power values are related to the attainment of social status and prestige, and the control and domination over people and resources (Schwartz, 1994). The marker values for Power are social power, public image, authority and the right to lead, and wealth, material possessions, and money (Ralston et al., 2011).

For participants drawing on Power, wealth was often a prevalent motive. Environmental initiatives were undertaken to increase the competitiveness of the business. These participants pursued environmental initiatives to gain new business or to save costs but tended to be reluctant to pursue any initiatives that did not promise quick cost savings or competitiveness gains.

[Reducing business travel] is good for us because, obviously, we're dealing with something potentially quickly, we can then get on with other work, so we're more productive. And, of course, think of all those overheads you're saving, wear and tear on the vehicle, the fuel, the guy's time, it's all dead time, isn't it, travelling. It's all savings and we've just got our financial year end figures from our accountant, and our margin is up nearly $10 \%$ from the year before. (Caroline-M15) 
Others linked proenvironmental behaviors with the desire to maintain a favorable public image.

The big thing that we've done, which ... was partly environmental and partly technical, was to spend a lot of money on the [heating and ventilating system] because it was on its last legs ... It cost about $£ 80,000$. Now I wouldn’t want people just to see it as a veneer to win business but you've got to be seen to provide an energy rating when you lease or sell property and ... an F rating would have reduced the value of it. (Robert-M14)

Self-direction and security values. Some Type 1 managers drew on Self-Direction values - which stem from a need for autonomy and independence and are characterized by the marker values independent, self-reliant, self-sufficient; choosing own goals; freedom of action and thought; creativity, uniqueness, imagination; curious, interested in everything (Ralston et al., 2011) - to express their skepticism of a proenvironmental agenda and their dislike of being compelled by others to take proenvironmental actions.

Don't drive your car there, you should cycle. Well, how many lorries have got to deliver enough food that I can eat enough calories that I can cycle there? People should leave folk alone and let them make their own minds up. (M17)

Both Type 1 and Type 2 managers - even if skeptical of global environmental threats as Type 1 managers often were - might draw on Security values (characterized by the marker values social order, stability of society; national security; family security, safety for loved ones) to express concern over potential risks to national security and stability from environmental disturbance and competition for natural resources.

Quite frankly, I don't see how human beings drive climate change.... [But] oil is running out.... We have to plan our way out of being dependent on energy from other nation states that aren't stable. We have to reduce our dependency on ... competitors. (M11)

When you look into what's supposedly in store as far as oil reserves running out ... about how costs are going to spiral, I mean, it's just horrific. So if you look at the sheer economics, the logistics in being able to continue to get at those resources, obviously it's alarming. And that's partly in our lifetime but certainly in our children's and now my grandchild's time. (Caroline-M15)

Benevolence values. In the above quote, Caroline's Benevolence values (concern for the welfare of children and grandchildren) overlap with Security values (particularly concern for family security). This is consistent with 
Schwartz and Bilsky's (1990) assertion that adjacent value domains will show some overlap in the marker values. Benevolence values relate to a concern with the preservation and enhancement of the welfare of people with whom one is in frequent contact (Schwartz, 1994) and include the marker values loyalty to friends and group; honesty, genuineness, and sincerity; helpfulness and working for the welfare of others; and responsibility, dependability, and reliability (Ralston et al., 2011).

Type 2 managers often related environmental issues to people who they knew well, for example, staff or their local community, but could find it more difficult to relate to environmental issues that affected unknown people far away.

... because it's human nature, isn't it, climate change is about what affects you, you can see what's going on in Japan, and Tsunamis and things. So many people, wherever you are, people focusing on their little, insular lives. And it's a bit tragic but it doesn't affect me. [. . .] That's over there, that doesn't affect us. (M23)

Constructions of environmental engagement by Type I and Type 2 managers. Type 1 and Type 2 managers were not entirely uninterested in proenvironmental action. For example, Robert (Type 1) invested in a more efficient heating and ventilating system, replacing a worn-out system with a poor energy rating that would deter other businesses from renting or buying space on his premises. Caroline (Type 2) took up the opportunity of a free environmental audit and pursued some initiatives that reduced both costs and environmental impact, such as conducting business by phone rather than sending employees to clients' premises. She also recognized that schemes such as carbon offsetting (paid for by customers), had gained her environmental credibility. However, they were less interested in projects requiring significant capital investment such as low energy lighting.

Participants drawing on Power values tended to express interest in environmental initiatives with an identifiable benefit for competitiveness. Examples included recycling ink cartridges, because they could, "drive down costs and [provide] a quick bang for our buck" (M21).

Type 1 and Type 2 participants could be skeptical of human responsibility for climate change, suggesting that "what's the cause and what's the effect is a little bit cloudy" (M17) and see it as too big a problem for them to understand or do anything about. Type 2 managers might, however, express a wish to "do things for the environment as long as there's some sort of return for me" such as a company car that "gives less emissions, less taxes, better fuel economy" (M21). 


\section{Drawing on Achievement-Type 3 and Type 4 Managers}

As in the previous section, we first analyze the principal marker values for these types: Achievement, Benevolence, Universalism, Self-Direction, and Tradition. We then consider how these participants drew on them to construct their environmental engagement.

Achievement values. Achievement values relate to personal success through demonstrated competence and include the marker values being influential, having an impact; successful, achieving goals; and capable, competent, effective, and efficient (Ralston et al., 2011). A person motivated by Achievement values not only needs to feel influential, efficient/effective, capable, and so on, but also needs to be recognized as such by their peers.

Many interviewees drew on Achievement values, mainly in terms of influencing others to make a difference and in feeling capable, competent, efficient, and effective in bringing about proenvironmental change. Being influential and having an impact on people and events was clearly something that was important to many interviewees. They identified opportunities to engage staff and influence other businesses through words and by example.

We see ourselves as very much on the leading edge of [environmental innovation]. But what society will allow is always changing and if you're ... helping to push it in a certain direction, and seeking to make environmental sustainability issues more important, then the base line is always moving in the right direction. (Lawton-M10)

I think it's important to show people that we all need to do our bit to reduce climate change and so I like to set an example ... (M19)

The need to be seen as capable, competent, efficient, and effective was evident when interviewees talked about the ability to see environmental issues in terms of components that could be addressed in a manageable way and thus rendered complex environmental issues more tractable.

Yes there are technological challenges but ... every time [people are] building something new, they're thinking about it, every engineer, every builder is thinking how can we make this more efficiently, how can I make this better... (M22)

Individuals drawing primarily on Achievement values were, like their Type 1 and Type 2 counterparts, also conscious about the need to balance cost with environmental (and other) benefits. However, they spoke less about the 
extrinsic purposes of environmental engagement in improving the economic performance of the business and more about the intrinsic sense of feeling competent, successful, and making a difference. They did not express the resistance or skepticism toward notions of global environmental problems displayed by those drawing on Power.

Benevolence values. Both Type 3 and Type 4 managers would draw on Benevolence values. In doing so, they stressed collegiality and working together through their environmental engagement. Loyalty to friends and community and working for the welfare of others was important, not simply because an interviewee felt responsible for the longer term well-being of these people but because it gave an immediate sense of pleasure and belonging.

... this company ... operates very much on the basis of consensus and not competition or complication. . . It's having always been sensitive to environmental matters . . . and then having kids and being aware of what the future may hold for them. . . I think it's true of most people here, you know, it's not just a job of work, it's a calling as well. We want to make the world a better place. (Lawton-M10)

It's so enjoyable to know your producers ... and when you get to know them as people, you've got a community but also you know that ... you're minimizing the damage to the environment by reducing food miles and congestion and travel. (M5)

Honesty, sincerity, and genuineness were important to some managers, in the sense of needing a consistent fit between who they were, what they did, who they worked with and what they believed, as evidenced in the quote below from Lawton.

It means my business approach to sustainability and the environment is very strongly a part of my own approach to things; the way that I live my own life so you have to walk the walk if one is talking the talk. So I don't advocate that anyone does anything that I'm not prepared to do myself. (Lawton-M10)

Universalism values. Type 4 managers were the only ones who would draw on Universalism values, which are related to the understanding, appreciation, tolerance, and protection of the welfare for all people and for nature. They include the marker values equality; world at peace, free of conflict; unity with nature; wisdom, a mature understanding of life; a world of beauty, the arts and nature; social justice; and protecting the environment (Ralston et al., 2011). 
Several interviewees drew explicitly on environmental protection and unity with nature, Universalism values that have the most direct connection with environmental engagement.

We maintain that sustainability is an integral part of everything we do. Therefore it's not a sort of greenwash that comes at the end of the process .... It's about from the beginning, the planning and design process, through to the end product, it's sustainability, it's fundamental to it all. (Lawton-M10)

I think the world we live in is much more complex than we appreciate and I believe that whatever we throw at it, it will absorb and survive. However, we've now got humanity and whether that will survive is a different matter. ... We all throw it [plastic] away and once it's out of our vision it doesn't exist anymore. (M9)

They also drew on less overtly environmental Universalism marker values, such as equality and social justice, to argue that the perpetuation of global environmental problems was morally wrong, unfair, and unjust.

The more greedy we are for resources, the more disadvantaged the poor get, so it's probably the bigger picture of the effect on ... the poor of the world ...., which is probably the more moral way to look at it. Undoubtedly there's people who are living on the edge who will be pushed off the edge by climate change and by the greed of the developed countries ... (M1)

Self-direction values. Some Type 3 and Type 4 participants drew on SelfDirection, which is related to curiosity, creativity, independent thought and action as well as autonomy. Unlike Type 1 participants, who might invoke self-direction to resist the imposition of environmental policies, these individuals made a positive link between environmental engagement and marker values, such as independence, setting their own goals, and being creative in finding solutions and setting their own plans for environmental improvement. This focus on action seemed to resonate with the Achievement values these managers drew upon.

We tried everywhere to get the hydrogen-fuel cells and I became fascinated by the whole idea and learned a lot of new things. In terms of the climate and global warming, I learned that even doing small things you can achieve quite a difference, it just needs a little bit of time, a bit of creativity, and curiosity. (M7)

Drawing on tradition values. While this value domain was only drawn upon by one participant, Suzanne (M24), the combination of Achievement, 
Benevolence, and Tradition values makes her a striking example of Type 3. Suzanne was strongly influenced by her father, the former owner, who she described as both highly concerned for the welfare of family and employees and for the conservation of nature.

We have long-standing staff with a really solid ethos. My father . . led by example and ... engendered loyalty. ... My father was a true countryman ... it meant a lot to him that he wouldn't be damaging the world, the countryside in particular. . . He didn't want to be responsible for making money out of damaging the planet in any way.... Sustainability is our big thing, always has been, will continue to be and we'll never compromise on that. (Suzanne, M24)

Constructions of environmental engagement by Type 3 and Type 4 managers. Type 3 and Type 4 participants described a number of environmental actions, some of which suggested substantial personal engagement. For example, Lawton had initiated multiple projects, such as switching to recycled products and installing low energy lighting. However, he was also trying to work at a deeper level with employees and customers to effect more fundamental environmental change. For example, he argued that,

[Global environmental issues] require us to press people to change their habits, be it to do with travel on business or to and from the office, or their tendency to think they can walk into the office in a T-shirt on a December day and it'll be nice and warm. Just trying to get people to understand the implications of what they do, which is closely aligned to the policy of this company as we're trying to operate in as sustainable a way as possible. (Lawton, M10)

Suzanne (M24) had also taken a number of more demanding proenvironmental measures. For example, her company had installed a rainwater collection system, was developing its own woodland, and had installed an expensive wood burner, the stated aim being to increase efficiency and source raw materials more sustainably.

Type 3 and Type 4 participants were more likely than their Type 1 and Type 2 counterparts, to describe environmental concerns responses in localized and personalized terms.

East Anglia will change because we are an agricultural area . . . If climate changes and it means agriculture has to change, then I'd say the landscape will change. ... It is happening on our doorsteps. (M20)

They were also more likely to accept that climate change was caused by humans and to accept personal responsibility for dealing with climate change and other major environmental issues. 
Man is undoubtedly having an impact but, if you look back on history, the world has gone through drastic climatic changes before. The difference now is that this is being accelerated and therefore I don't think man has created climate change but I think man is accelerating climate change. (Suzanne-M24)

It's a personal sense that I think we can all make a difference and if we all made a little difference it would make a big difference. (M20)

If it's going to go wrong I don't want to add to that wrong. (M7)

Type 4 participants in particular were often uncomfortable or critical of competitiveness motivations for environmental engagement, seeing much it as show rather than substance and not conducive to genuine environmental improvements.

You've got to be cynical of companies who get on the bandwagon and make a lot of noise about what they're doing when they were not doing anything before. It's all peacock feathers and show. (M16)

They also expressed the pragmatic concern that undertaking proenvironmental action on cost-saving grounds alone would mean that improvements would stop as soon as the financial savings ceased: "What happens when we get to the end of that process and the savings have stopped? How do we encourage them to do things better then?" (M5).

Rather than using the language of "win-win," they described wanting to make a difference through influencing others, to reduce wastefulness, and to work collaboratively, for example, by "sorting the materials in a more efficient way and ... exploring working with other companies that can use some of our waste" (M24).

\section{Discussion and Conclusion}

In this final section, we discuss the theoretical and practical implications of our findings and outline a research agenda building on our study.

\section{Theoretical Implications}

Our study makes a contribution to knowledge by applying existing theory in the form of the SVS to the phenomenon of SME environmental engagement (cf. Crane et al., 2016). A systematic qualitative analysis based on the 10 value domains identified in the SVS allows us to capture the "value-laden processes" of SME environmental engagement to go beyond the "binary logic of business vs. society" (Poldner et al., 2017, p. 215). This provides a 
robust theoretical basis for the development of a typology of SME managers that extends on previous work, such as Spence and Rutherfoord's (2001) matrix of SME managers' social responsibility based on their profit and societal orientations or other studies that have concentrated on the broader distinction between self-enhancing and self-transcending values (Florea et al., 2013; Fritzsche \& Oz, 2007; Ng \& Burke, 2010).

First, the main distinction in our typology is between managers drawing on Power and managers drawing on Achievement-both self-enhancing value domains, which nonetheless seemed to shape participants' understandings quite differently in the specific practice context of this study. This is in contrast with earlier findings (Fritzsche \& Oz, 2007) that selfenhancing values were generally not conducive to business social and environmental engagement. As far as we could ascertain, Achievement values have not previously been considered separately in relation to business environmental engagement. Our finding, that participants who drew on Achievement also drew on Benevolence and/or Universalism, challenges Schwartz and Bilsky's (1987, 1990) original assertion that Achievement will generally be tension with "concern for others," but supports their (Schwartz \& Bilsky, 1990) suggestion that the action contexts in which values are elicited exerts an influence on the values that are seen to be harmonious or in tension.

Second, our findings highlight the importance of Benevolence values in supporting SME managers' environmental engagement, which were compatible with both Achievement and Power values. For many managers, concern for the future welfare of others that are close to oneself may be easier to link to business behavior than the more distant and abstract concern for universal goods such as environmental protection or social justice. This would seem congruent with Schwartz and Bilsky's $(1987,1990)$ original findings that Benevolence values were particularly prevalent across different cultures. However, a focus on Benevolence values seems to have been somewhat lost in previous research that works with the broader distinction between selfenhancing and self-transcending values.

Third, the fact that values on the openness-to-change versus conservation axis did not serve as distinguishers in our typology should not obscure the fact that these values were drawn upon by many participants and thus seem to have an important role to play in supporting SME environmental engagement. The potentially significant role of these values, particularly Conformity, Security, and Self-direction, tends to be obscured in research focusing on the self-enhancing versus self-transcending axis. Conformity values were related to the importance that managers attached to regulatory compliance. It seems plausible that inconclusive results of previous research into the importance of 
regulation in motivating SME environmental engagement (Baden et al., 2009; Cassells \& Lewis, 2011; Vickers et al., 2009) could be partially explained by variations in the prevalence of Conformity values.

\section{Implications for Policy and Practice}

Individual values have a key role to play in promoting environmental engagement. Two leading climate change communicators characterize this challenge as, "weaving poetry and prose" to inspire people to care about the problem, and argue that "[f]undamentally, this means engaging with people's values" (Corner $\&$ Clarke, 2017, p. 48). Building on Spence and Rutherfoord's (2001) conclusion that different policy approaches are needed to engage owner-managers operating under different business-society frames, we offer some suggestions as to how policies aimed at increasing SME environmental engagement might draw on the different value configurations identified in our study.

First, win-win arguments continue to be used in environmental messages aimed at SMEs, for example, in the U.K. Carbon Trust's aim to "help companies turn good environmental performance into competitive advantage" (Carbon Trust, n.d., n.p.), but may not prove effective in engaging many SME managers. Type 1 and Type 2 managers in our study did draw on Power values relating to wealth and competitiveness but they did not simultaneously draw on Universalism values and are therefore unlikely to be strongly motivated by the "saving the planet" element of the win-win argument. Type 1 managers may, however, be motivated by messages that emphasize the risks to security emanating from global environmental problems. Type 2 managers, who also drew on Benevolence values, may be susceptible to a reframed win-win argument that stresses protection of family, friends, community, and coworkers.

Second, messages that frame environmental engagement in terms of achievement and the satisfaction to be gained from being able to make a difference are likely to appeal more strongly to Type 3 and Type 4 managers than messages stressing competitiveness or cost savings. This is not necessarily because they do not care about costs or profitability but because they do not frame their environmental engagement in these terms. For these manager types, appeals to Benevolence values such as protection of family, friends, community, and coworkers seem promising. Messaging that focuses exclusively on environmental protection or social justice is only likely to appeal to the minority of managers who draw primarily on Universalism values. For many other SME managers, engagement messages might actually prove more effective if they were reframed in terms of protection of loved ones and personal achievement. 
Our study also suggests that SME managers may find it helpful to consider their own values as they seek to navigate these issues. This finding echoes Spence and Rutherfoord's (2001) suggestion that owner-managers may benefit from understanding their own frames around the business-society relationship. We have adopted this approach in our own practical work with SME managers through local business support organizations, by starting with an exploration of managers' individual values. The response from workshop participants suggests that this is helpful, enabling them to link environmental and business issues more easily than through generic "win-win" messages.

\section{Agenda for Future Research}

Future research into values and business environmental engagement will benefit from looking at the whole range of value domains identified in the SVS and not focus only on the self-enhancement versus self-transcendence axis.

Our typology of managers could be tested and further refined through further qualitative and quantitative research to establish whether the types we identified are robust in other cultural or sectoral settings and, if so, how prevalent each of the types are in a more general population of SME managers. It would also be useful to investigate the link between the SME manager idealtypes we propose and the environmental behaviors shown by firms in more depth as well as with larger samples.

It would also be worthwhile exploring whether some of the value configurations we identified are more prevalent in particular contexts such as familyowned businesses where there is some evidence of better environmental and social performance in comparison with other firms (Berrone et al., 2010).

Future research on the inherent tensions in environmental and social engagement (cf. Hahn et al., 2015; Van der Byl \& Slawinski, 2015) could benefit from an explicit and systematic investigation of managers' value configurations and how they relate to particular coping strategies. For example, do different types of SME managers (according to our typology) employ different strategies as they seek to reconcile social, environmental, and commercial demands? It would also be useful to investigate whether similar ideal-types can be identified in larger firms and, if so, how their values relate to organization-level engagement.

Finally, we believe that the methodology we employed holds significant promise for future empirical work in this area. By combining the analytical rigor of the SVS with the depth and richness afforded by qualitative evidence, we were able to add considerable nuance to our findings. This approach could benefit research on social and environmental engagement in other organizational contexts and could be adapted to address a range of other values-related questions. 


\section{Appendix}

\section{Interview Prompts}

The business

- Can we start off with some brief background about the business?

- Can you tell me (remind me) about what your business does and your role in this?

- Where do you see the business going in the future?

- How do you see your business in the wider marketplace?

- How far can your company influence this?

- What helps and hinders you in this?

\section{Environmental issues}

- How do you view environmental issues in your business?

- What sort of environmental things do you do?

$\circ \quad$ What is your role in this?

- Why are you doing the environmental initiatives you're doing?

- How has environmental legislation influenced what you do?

- What about saving money through efficiency gains?

- Or other business issues like competition, reputation, tendering?

- How do you see your own role in this?

- Are there any particular issues that influence what you do?

- How have your ideas about this changed over time?

- What do you think other business like yours think?

- Have you seen a change in how businesses think about greening (since we last met)?

- What messages do you hear about being greener at work?

\section{Global environmental issues}

- What bigger issues do you link being greener with?

- Where does climate change fit into that?

- What does climate change mean to you?

- How have your ideas about climate change changed over time?

- How do you think other people make sense of climate change?

- What do you think other companies like yours think about climate change?

- And what about business greening-how is it linked or separate?

- What do you think should be done about climate change?

- What does climate change mean to you in relation to other issues of concern? 


\section{Acknowledgments}

We are indebted to the associate editor of Business \& Society and three anonymous reviewers for their constructive comments, which assisted us greatly in shaping this final version of the article. We also gratefully acknowledge the helpful comments of our colleagues at the Open University, Michael Ngoasong, Owain Smolović Jones, and Siv Vangen, on an earlier version of the article. Any remaining errors are, of course, entirely our own.

\section{Declaration of Conflicting Interests}

The authors declared no potential conflicts of interest with respect to the research, authorship, and/or publication of this article.

\section{Funding}

The authors disclosed receipt of the following financial support for the research, authorship, and/or publication of this article: This research was supported by a doctoral grant from the Open University, UK.

\section{References}

Agle, B. R., \& Caldwell, C. B. (1999). Understanding research on values in business: A level of analysis framework. Business \& Society, 38, 326-387.

Arikan, G., \& Ben-Nun Bloom, P. (2015). Social values and cross-national differences in attitudes towards welfare. Political Studies, 63, 431-448.

Baden, D. A., Harwood, I. A., \& Woodward, D. G. (2009). The effect of buyer pressure on suppliers in SMEs to demonstrate CSR practices: An added incentive or counter-productive? European Management Journal, 27, 429-441.

Berrone, P., Cruz, C., Gomez-Mejia, L. R., \& Larraza-Kintana, M. (2010). Socioemotional wealth and corporate responses to institutional pressures: Do family-controlled firms pollute less? Administrative Science Quarterly, 55, 82113.

Boiral, O., Baron, C., \& Gunnslaugson, O. (2014). Environmental leadership and consciousness development: A case study among Canadian SMEs. Journal of Business Ethics, 123, 363-383.

Brammer, S., Hoejmose, S., \& Marchant, K. (2012). Environmental management in SMEs in the UK: Practices, pressures and perceived benefits. Business Strategy \& the Environment, 21, 423-434.

Cambra-Fierro, J., Hart, S., \& Polo-Redondo, Y. (2008). Environmental respect: Ethics or simply business? A study in the small and medium enterprise (SME) context. Journal of Business Ethics, 82, 645-656.

Carbon Trust. (n.d.). Business advice. Retrieved from https://www.carbontrust.com/ client-services/advice/business-advice/

Cassells, S., \& Lewis, K. (2011). SMEs and environmental responsibility: Do actions reflect attitudes? Corporate Social Responsibility and Environmental Management, 18, 186-199. 
Chin, M. K., Hambrick, D. C., \& Treviño, L. K. (2013). Political Ideologies of CEOs: The influence of executives' values on corporate social responsibility. Administrative Science Quarterly, 58, 197-232.

Corner, A., \& Clarke, J. (2017). Talking climate: From research to practice in public engagement. London, England: Palgrave Macmillan.

Crane, A., Henriques, I., Husted, B. W., \& Matten, D. (2016). What constitutes a theoretical contribution in the business and society field? Business \& Society, 55, 783-791.

Crompton, T. (2010). Common cause: The case for working with our cultural values. A report published in partnership by the Climate Information Outreach Project. Campaign for the Protection of Rural England, Friends of the Earth, Oxfam and WWF. Retrieved from http://assets.wwf.org.uk/downloads/common_cause report.pdf

Department for Business, Innovation and Skills. (2015). Business population estimates for the UK and regions 2015. London, England: Department of Business, Innovation \& Skills. Retrieved from https://www.gov.uk/government/uploads/ system/uploads/attachment_data/file/467443/bpe_2015_statistical_release.pdf

Desai, A., \& Rittenburg, T. (1997). Global ethics: An integrative framework for MNEs. Journal of Business Ethics, 16, 791-800.

Duarte, F. (2010). Working with corporate social responsibility in Brazilian companies: The role of managers' values in the maintenance of CSR cultures. Journal of Business Ethics, 96, 355-368.

Eisenhardt, K. M. (1989). Building theories from case studies. Academy of Management Review, 14, 532-550.

Elkington, J. (1994). Towards the sustainable corporation: Win-win-win business strategies for sustainable development. California Management Review, 36(2), 90-100.

European Commission. (2011). A resource efficient Europe: Flagship initiative under the European 2020 Strategy (COM (2011) 21). Retrieved from https://www.eea. europa.eu/policy-documents/a-resource-efficient-europe-flagship

European Commission. (2016). Small and medium-sized enterprises (SMEs) and the environment. Retrieved from http://ec.europa.eu/environment/sme/index_en.htm

Florea, L., Cheung, Y. H., \& Herndon, N. C. (2013). For all good reasons: Role of values in organizational sustainability. Journal of Business Ethics, 114, 393-408.

Fritzsche, D., \& Oz, E. (2007). Personal values' influence on the ethical dimension of decision making. Journal of Business Ethics, 75, 335-343.

Gadenne, D. L., Kennedy, J., \& McKeiver, C. (2009). An empirical study of environmental awareness and practices in SMEs. Journal of Business Ethics, 84, 45-63.

Gioia, D. A., Corley, K. G., \& Hamilton, A. L. (2013). Seeking qualitative rigor in inductive research: Notes on the Gioia methodology. Organizational Research Methods, 16, 15-31.

Goodpaster, K. E., \& Matthews, J. B. (1982). Can a corporation have a conscience? Harvard Business Review, 60(1), 132-141.

Hahn, T., Pinkse, J., Preuss, L., \& Figge, F. (2015). Tensions in corporate sustainability: Towards an integrative framework. Journal of Business Ethics, 127, 297-316. 
Hemingway, C. A., \& Maclagan, P. W. (2004). Managers' personal values as drivers of corporate social responsibility. Journal of Business Ethics, 50, 33-44.

Jamali, D., Lund-Thomsen, P., \& Jeppesen, S. (2017). SMEs and CSR in developing countries. Business \& Society, 56, 11-22.

Jansson, J., Nilsson, J., Modig, F., \& Hed Vall, G. (2017). Commitment to sustainability in small and medium-sized enterprises: The influence of strategic orientations and management values. Business Strategy \& the Environment, 26, 69-83.

Kearins, K., Collins, E., \& Tregidga, H. (2010). Beyond corporate environmental management to a consideration of nature in visionary small enterprise. Business \& Society, 49, 512-547.

King, N. (2004). Using templates in the thematic analysis of texts. In C. Cassell \& G. Symon (Eds.), Essential guide to qualitative methods in organizational research (pp. 256-270). London, England: SAGE.

Lincoln, Y. S., \& Guba, E. G. (1985). Naturalistic inquiry. London, England: SAGE. Mirosa, M., Lawson, R., \& Gnoth, D. (2013). Linking personal values to energyefficient behaviors in the home. Environment \& Behavior, 45, 455-475.

Mudrack, P. (2007). Individual personality factors that affect normative beliefs about the rightness of corporate social responsibility. Business \& Society, 46, 33-62.

$\mathrm{Ng}$, E., \& Burke, R. (2010). Predictors of business students' attitudes to sustainable business practices. Journal of Business Ethics, 95, 603-617.

Onkila, T. J. (2009). Corporate argumentation for acceptability: Reflections of environmental values and stakeholder relations in corporate environmental statements. Journal of Business Ethics, 87, 285-298.

Poldner, K., Shrivastava, P., \& Branzei, O. (2017). Embodied multi-discursivity: An aesthetic process approach to sustainable entrepreneurship. Business \& Society, 56, 214-252.

Porter, M. E., \& Kramer, M. R. (2011). Creating shared value. Harvard Business Review, 89(1/2), 62-77.

Ralston, D. A., Egri, C. P., Reynaud, E., Srinivasan, N., Furrer, O., Brock, D., ... Hallinger, P. (2011). A twenty-first century assessment of values across the global workforce. Journal of Business Ethics, 104, 1-31.

Rathburn, B. C., Kertzer, J. D., Reifler, J., Goren, P., \& Scotto, T. J. (2016). Taking foreign policy personally: Personal values and foreign policy attitudes. International Studies Quarterly, 60, 124-137.

Revell, A., \& Blackburn, R. (2007). The business case for sustainability? An examination of small firms in the UK's construction and restaurant sectors. Business Strategy \& the Environment, 16, 404-420.

Revell, A., Stokes, D., \& Chen, H. (2010). Small businesses and the environment: Turning over a new leaf? Business Strategy \& the Environment, 19, 273-288.

Rokeach, M. (1968). Beliefs, attitudes and values: A theory of organization and change. San Francisco, CA: Jossey-Bass.

Rothenberg, S., \& Levy, D. L. (2012). Corporate perceptions of climate science: The role of corporate environmental scientists. Business \& Society, 51, 31-61.

Schwartz, S. H. (1994). Are there universal aspects in the structure and contents of human values? Journal of Social Issues, 50(4), 19-45. 
Schwartz, S. H. (2004). Mapping and interpreting cultural differences around the world. In H. Vinken, J. Soeters \& P. Ester (Eds.), Comparing cultures: Dimensions of culture in a comparative perspective (pp. 43-73). Leiden, The Netherlands: Brill.

Schwartz, S. H. (2012). An overview of the Schwartz Theory of Basic Values. Online Readings in Psychology and Culture, 2(1). Retrieved from http://scholarworks. gvsu.edu/orpc/vol2/iss1/11/

Schwartz, S. H., \& Bilsky, W. (1987). Toward a universal psychological structure of human values. Journal of Personality and Social Psychology, 53, 550-562.

Schwartz, S. H., \& Bilsky, W. (1990). Toward a theory of the universal content and structure of values: Extensions and cross-cultural replications. Journal of Personality and Social Psychology, 58, 878-891.

Segal, L., \& Lerner, M. (2013). The conflict of ethos and ethics: A sociological theory of business people's ethical values. Journal of Business Ethics, 114, 513-528.

Spence, L. J. (2016). Small business social responsibility: Expanding core CSR theory. Business \& Society, 55, 23-55.

Spence, L. J., \& Rutherfoord, R. (2001). Social responsibility, profit maximisation and the small firm owner-manager. Journal of Small Business and Enterprise Development, 8, 126-139.

Van der Byl, C., \& Slawinski, N. (2015). Embracing tensions in corporate sustainability: A review of research from win-wins and trade-offs to paradoxes and beyond. Organization \& Environment, 28, 54-79.

Vickers, I., Vaze, P., Corr, L., Kasparova, E., \& Lyon, F. (2009). SMEs in a low carbon economy: Final report for BERR Enterprise Directorate. London, England: Department of Business, Innovation \& Skills. Retrieved from https:/eprints.mdx. ac.uk/4163/1/SMEs_in_a_low_carbon_economy.pdf

Whitmarsh, L., \& Corner, A. (2017). Tools for a new climate conversation: A mixedmethods study of language for public engagement across the political spectrum. Global Environmental Change, 42, 122-135.

Williams, S., \& Schaefer, A. (2013). Small and medium-sized enterprises and sustainability: Managers' values and engagement with environmental and climate change issues. Business Strategy \& the Environment, 22, 173-186.

Willows, R., \& Connell, R. (Eds.). (2003). Climate adaptation: Risk, Uncertainty and decision-making (UK Climate Impacts Programme Technical Report). Retrieved from http://www.ukcip.org.uk/wp-content/PDFs/UKCIP-Risk-framework.pdf

Wöhrmann, A. M., Fasbender, U., \& Deller, J. (2016). Using work values to predict post-retirement work intentions. Career Development Quarterly, 64, 98113.

\section{Author Biographies}

Anja Schaefer (DPhil, University of Buckingham) is a senior lecturer in management in the Department for Public Leadership and Social Enterprise at the Open University, UK. Her research interests focus on sustainability in business organization and organizational ethics in both private and public sector organizations. Her 
articles have appeared in journals such as Business Ethics: A European Review, Business Strategy and the Environment, Corporate Social Responsibility and Environmental Management, Journal of Business Ethics, and Journal of Management Studies.

Sarah Williams ( $\mathrm{PhD}$, Open University) is a senior lecturer in the Department for Strategy and Management at the University of Bedfordshire, UK. Her teaching and research interests focus on business sustainability and, in particular, the role of the individual. She has previously published in Business Strategy \& the Environment and several edited books.

Richard Blundel ( $\mathrm{PhD}$, University of Birmingham) is a professor of enterprise and organization in the Department for Public Leadership and Social Enterprise at the Open University, UK. His research, which examines the nature and implications of growth and innovation in manufacturing businesses, craft-based firms, and social enterprises, has been published in journals such as Enterprise \& Society, Entrepreneurship \& Regional Development, The European Journal of the History of Economic Thought, Industry \& Innovation, and Journal of Small Business Management. 